SHS Web of Conferences 7, 01003 (2014)

DOI: $10.1051 /$ shsconf / 20140701003

C) Owned by the authors, published by EDP Sciences, 2014

\title{
Study on Imbalance Development of China's Economic Growth and Income Distribution
}

\author{
Zhang Zhenjia \\ College of Business and Management, Shenyang University, 110041 Shenyang Liaoning, China
}

\begin{abstract}
In the past 30 years, China's economy has scored remarkable achievements named as a miracle of economic growth. During that period, income levels and wealth of Chinese people have been a huge increase and improvement. At the same time, we cannot deny the fact that economic growth and uneven income distribution is a developing trend: increasing people's income growth rate is lower than the growth rate of gross national income; income distribution abnormalities, and the gap between the poor and rich is widened. With statistical data, this thesis tries to reveal the typical fact of China's rapid economic growth since 1978 first, then discussing the status of distribution of income and degree of abnormal development. Finally, this thesis puts forward some countermeasures.
\end{abstract}

Keywords. economy development; income distribution; imbalance development

\section{Typical facts of China's economy growth}

China's economic reform and economic restructuring have been carried out for more than 30 years. In that period, driven by the economic transformation policy, the consecutive and rapid growth of economy is wide known as "China miracle" around the whole world. Compared data of 1978 and that of 2012, we can see that Gross National Income(GNI) increased by 141.63 times from 364.52 billion yuan in 1978 to 51.6 trillion yuan in 2012 and during the same period, GNP per capita has experienced a 100.84 times growth from 381 yuan to 384,20 yuan ${ }^{[1]}$. That is to say that from the perspective of national accounts, achievements of China's economic catch-up is definitely remarkable.

Compared with other major countries in the same period, China's economy has been playing a dominant role in the global economy. China's rapid economic growth narrowed the gap with developed countries in the world, and the international status and rankings of China's economy are both on the rise. GDP rose from the $10^{\text {th }}$ place in 1978 to the $2^{\text {nd }}$ in 2012 and GDP per capita has increased by more than 60 ranking places as well during the same period.

\section{Residential income analysis: increment speed and abnormal distribution}

${ }^{[1]}$ Data used in this paper comes from China Statistical Yearbook 2013 and calculated by author according the Yearbook. 
First of all, there is a striking fact that the level of income and wealth of our residents in the past 30 years of reform and opening-up has been greatly improved. Per capita disposable income of urban households increased 71.53 times in 2012 than that in 1978. In the meantime, per capita net income of rural households increased 59.26 times. Engel coefficient of household consumption constitutes of both urban and rural residents are dropped substantially in the past 30 years. But we can not ignore the fact that the increment speed of income growth is less than that of national income growth. That is to say, residents did not fully share the growing economic well-being together with the country. According to the experience of developed countries, the portion of labor income in national income will increase with economic growth. It will rise up to about $70-75 \%$, while which is called a steady state. Unfortunately, China's situation was the opposite during the last 30 years, which can be proved by the proportion of gross amount of labor income in GDP. Even though both gross amount of labor income and GDP increased sharply from 1978 to 2012, the proportion decreased from $15.6 \%$ in 1978 to $13.4 \%$ in 2012 and to the bottom point of $11 \%$ in 2000 .

Chinese government was apt to emphasize equity instead of efficiency in the field of income distribution before adopting reform and opening-up policy, resulting in lack of necessary economic development incentives and production inefficiencies. At the beginning of the reform, "Let some people get rich first" policy was to overcome the egalitarian income distribution, strengthening incentives to improve efficiency and eventually achieve common prosperity. The reform and development experience in past 30 years has shown that the general trend of development never lost the goals of that kind of policy. However, in transition, changes in income distribution are more complicated than originally thought. Along with economic growth, the overall gap of personal income distribution has gone through the process from a narrow gap to the gradual spread. According to World Bank estimates, China's Gini coefficient was 0.31 in 1978, rising to 0.474 in 2012. Some foreign scholars are also very concerned about China's Gini coefficient. They believe that the Gini coefficient integrated by both urban and rural areas must be more than 0.5 which is much higher than the official statistics (Dwayne, Brandt, Giles \& Wang, 2005). [1] China is becoming a country with a big gap of income distribution. Based on the The World Bank Development Report 2005, according to the order from low to high order, China's Gini coefficient in 120 countries and regions was ranked as 85, which is close to some of Latin America and Africa countries with serious social divisions and economic stagnation.

Under the dual economic structure in China, with the rapid economic growth, the income gap between urban and rural residents in China continued to expand, which has aroused much attention of academia and government. In 1978, per capita disposable income of urban residents was as 2.57 times as per capita net income of rural residents. In 2007, the per capita net income of rural residents increased by $9.5 \%$, the highest growth rate since 1985 year. However, the income ratio of urban and rural residents has expanded to 3.36 in 2008, the biggest gap since the reform and opening up of the year and then went down slightly to 3.1 in 2012. In the recent 5 years, although the income of farmers has increased rapidly with the cumulative 2000 yuan per capita, the growth rate still lagged behind urban residents, broadening the income gap between urban and rural residents year after year. From a global perspective, China's income gap between urban and rural residents is much higher than many other countries. World Bank report pointed out that most of the world's urban-rural income ratio is 1.5, and the ratio above 2 is extremely rare. Compared with data of China, China is likely to have become one of the countries possessing the world's highest urban-rural income gap.

\section{Countermeasures to resolve imbalances}

As China's overall income level is still very low, the main task now is to accelerate development, improving the income level of the whole society. It is not wise to artificially narrow income gap at the expense of economic growth. Mobilizing all positive factors to maintain fast economic growth rate is still truly critical. Contemporarily, it should be tolerated that the temporary income gap continues to expand in a short time due to the increase in property income or other causes. But we should pay attention to income distribution, and gradually take measures to curb the widening income gap. 


\subsection{Establishing the "shared" model of development}

China's future development must follow the new growth concepts, implementing the new growth patterns. New growth patterns should not only emphasize the growth of the economy itself, while emphasizing economic growth for the purpose of improving people's well-being, focusing on the coordination of economic growth and social development, fostering the unities of patterns and purposes of economic growth. This new notion can be called up to "shared" model of growth. "Shared" model of growth is a summary of lessons learned from economic growth in developing countries and there has been no a unified and wide receiver definition so far.

Zhuang (2008)[2] pointed out that the so-called shared growth", that is, the growth of equality of opportunity, requires full play of market roles to promote rapid economic growth and in the meantime to take into account equality of opportunity, stating fair participation. In order to promote equality of opportunity, the government needs to work in three areas: first, to increase basic education, health and other social services inputs to improve the qualities and development potentials of people, especially vulnerable groups; secondly, to strengthen policy and fairness of the system to eliminate social injustice and create equal competition opportunities; third, to establish a social risk protection mechanisms for preventing and eradicating extreme poverty. Giving full play to market mechanism and promoting equality of opportunity and fair participation are complementary rather than contradictory. As long as more people more equal participate in the market, the market mechanism can be more fully exploited. Clearly, this new idea of shared economic growth is not only coincided with the "harmonious society" philosophy advocated by Chinese government but also consistent with "the transformation of economic growth" concept. Lehmann (2008) [3] proposed another concept Inclusive Growth-, which has a quite similar meaning with that of "Shared Growth". He argued that the basic meaning of inclusive growth is the share of economic well-beings. It involves issues of equality and equity, including measurable criteria and more intangible factors. The former includes the Gini coefficient as an indicator, the literacy rate, the general public goods supply and distribution, as well as education, health, electricity, water conservancy, transportation infrastructures, housing and personal safety; the latter includes ideas and feelings, of which the key word is hope and participation in society.

Specified to China's current stage of development, shared growth can be defined as the growth which promotes employment expansion and income equality. In other words, employment and income distribution in economic growth have special important roles. Enhancing employment and improving income distribution will stimulate economic growth in turn. In the meantime, employment and income equality will be enlarged and assured accompanied by the economic development (Lai,2009). [4]

\subsection{Improving the social security system and avoiding premature "welfare catch-up"}

Social security policy actually is kind of transfer payment. Government employs this kind of payment to adjust income distribution among social members and the same social members in different periods of time and mandatorily to arrange and ensure no income or low-income members of society to obtain the basic living conditions. Compared with foreign countries, Zhou (2008)[5] believed China's expenditure on social security and welfare lagged far behind other countries. The security and welfare spending in developed countries usually accounts for $30 \%$ to $50 \%$ of financial expenditure, and that in developing countries is about $20 \%$. However, in China, the proportion of pension and social welfare in overall financial expenditure has never up to $2 \%$ from 1978 to 2002 . China undoubtedly belongs to one of the countries with the lowest proportion. If we want to narrow the income gap, we must increase spending on social security, increasing the level of public social welfare.

However, China welfare policy can not copy the experience of developed countries and can not be too early to implement the "welfare to catch up". Proposals and researches on "welfare catch-up" started with the studies on the "lost decade" and "the Latin trap" in 1980s. In the development process, in order to cope with social trend of widening income gap, most of Latin American countries, prematurely copied and implemented a series of the social welfare system from developed countries, regardless of their level of income and financial capacity constraints, resulting in a deficit too large, 
domestic and foreign debt, triggering high inflation, debt crisis, financial crisis, economic crisis, eventually leading to economic stagnation. Fan and Zhang (2008) [6] argued that the stagnation of economic growth in Latin America and Asian countries showed us that it was not wise to foster "economic catch-up" with ignorance of phase of the development process, to pursuit "welfare catch up" without thinking of the financial constraints and to run after "redistributive goals" with neglect of the market mechanisms under government-led. As China's current economic development level is not high, which determines the level of the social security system is low. High social welfare and social security system will increase the company's labor costs, resulting in the reduction of employment opportunities. Meanwhile, the high social security spending will aggravate government burdens and slow down economic growth. Therefore, the level of social security must be apt to the phase of economic development in China in order to avoid falling into the "Latin American trap".

\subsection{Strengthening government regulation of the distribution of income by improving the tax system}

Firstly, it is necessary to perform personal income tax reform through strengthening the tax collection from high-income level people. At the same time, we should control strictly the proportion of employee benefits in total income of workers, and monitor the activities of enterprises that they regard products or services as employee benefits. Products and services as employee benefits should be implemented according to the principle of fair commercial transactions, not directly for the workers and their families, free or cheap to use in state-funded telecommunications, power, transportation, heat, water, gas and other enterprises. In addition, Zheng (2008)[7] put forward that government should also strengthen the following three aspects of the regulation on income distribution: first, timely applying the introductions of inheritance tax, gift tax, special consumption tax and other regulatory functions as personal income tax supplements, and gradually establishing a multi-tax coordination and cooperation system, which is covering the entire process of personal income adjustment; secondly, effectively reducing the tax burden of the low-income people especially the people living in rural areas; thirdly, strictly enforcing the law to avoid the frequent occurrence of the phenomenon of tax evasion.

\section{Conclusion}

Accompanied with China's current rapid economic growth, the share of residential income in gross national income is shrinking, and the income distribution gap is being larger. As can be said that, if we ignore the problem of income distribution deformities, it will not only endanger the nation's survival, development and long-term stability, but also will determine whether the future of the sustainability of rapid economic growth. Therefore, in order to solve this big and serious problem, this article points out that firstly we should update the idea of economic growth and establish "shared development model", which is necessary to emphasize the growth of the economy itself, while strengthening the social well-being development, that is to say, pursuing the unity of economic growth and social development. Secondly, it is vigilant that the government shall avoid premature "welfare catch-up" while Improving the social security system. According to China's present circumstances, raising the level of social security should be compatible with the development stage. Finally, as far as possible in order to ensure a fair distribution of income, government shall strengthen the roles of regulating the distribution of income by improving the tax system reinforcing the tax collection efforts on high income level groups.

\section{Acknowledgement}

This paper is funded by "2013 Shenyang Science and Technology and Planning Project-Development Path Study on Shenyang Modern Service Industry "(GN: F13-315-5-23). 


\section{References}

1. Dwayne B. Brandt. Giles \& Wang. Income Inequality during China's Economic Transition, www.msu.edu/ gilesj/BBGW.pdf.2005.7. 2005.

2. Zhuang Juzhong. Building a Harmonious Society with "Shared Growth": A Strategic Framework, In Lin Yifu, Zhuang Juzhong, Tang Min. \& Lin Tun (Eds.), Shared Growth toward a Harmonious Society[M]. Beijing: China Planning Press, 2008.

3. Lehmann, J.P. Exploring the "Inclusive" Growth[J]. Chinese Entrepreneurs, 2008(13):36.

4. Lai Guangsheng. Shared Growth Depends on Expanding Domestic Demand[J]. Academic Frontier of People's Forum, 2009:248.

5. Zhou Qingmei. Study on Income Distribution and Economic Growth in Transition Era[D]. Central Party School, 2008.

6. Fan Gang, Zhang Xiaojing. Welfare Catch-up and the Growth Trap: Lessons of Latin America, Management World[J]. 2008(9):97-105.

7. Zheng Lili. Analysis on the Conduct of China Government in Income Distribution at the Present Stage - Enlightenment from Sima Qian's “Good and Evil Study” [D]. Fujian Normal University, 2008 . 